\title{
Knowledge, Attitude, and Practice toward Skin Cancer Prevention and Detection among Jordanian Medical Students: A Cross-Sectional Study
}

\author{
Khaled Seetan $\mathbb{D}^{\mathbb{D}},{ }^{1}$ Almu'atasim Khamees $\mathbb{D}^{1},{ }^{1}$ Afnan Migdadi, ${ }^{1}$ Mosab Abu Shqeer, \\ Maram Jameel Hasan, ${ }^{1}$ Leen Ahmad Shatnawi, ${ }^{1}$ Tala Abu Bakr, ${ }^{1}$ and Nada Zayed ${ }^{3}$ \\ ${ }^{1}$ Department of Clinical Sciences, Faculty of Medicine, Yarmouk University, Irbid, Jordan \\ ${ }^{2}$ Faculty of Medicine, Hashemite University, Zarqa, Jordan \\ ${ }^{3}$ Department of Clinical Dermatology, Lincoln County Hospital, Lincoln, UK
}

Correspondence should be addressed to Almu'atasim Khamees; almotasem.kh@gmail.com

Received 19 December 2021; Accepted 27 January 2022; Published 14 February 2022

Academic Editor: Arash Kimyai Asadi

Copyright ( $) 2022$ Khaled Seetan et al. This is an open access article distributed under the Creative Commons Attribution License, which permits unrestricted use, distribution, and reproduction in any medium, provided the original work is properly cited.

Introduction. Skin cancer is one of the most growing types of cancer, especially in the Mediterranean, even though it is a preventable disease. The purpose of this study is to assess medical students' knowledge, attitude, and practice about skin cancer prevention and detection. Methods. A cross-sectional study was conducted using a validated structured questionnaire covering the areas of knowledge, attitude, and practice of the study participants. Results. The study involved 1530 students; $55.3 \%$ were females. Most of the students possessed proper knowledge about skin cancer (81\%). The most prevalent skin cancer risk factors were sun exposure during the day (83.5\%) and immunosuppression (71.2\%). More than half of the students did not have any habits of skin examination (61.5\%). $20 \%$ of the students never used sunscreen, while only $20 \%$ of them avoided sun exposure during day hours. Conclusion. The general level of the medical students' knowledge of skin cancer and its risk factors appeared to be higher than what is found in other studies; it is reasonable as the study participants were medical students. However, the protective behavior from the sun was inadequate when compared to the level of knowledge reported. Additional education about the behavior toward sun exposure and protection against skin cancer may be needed to be implemented in the dermatology curriculum.

\section{Introduction}

Skin cancer is the most common cancer in the United States, with an estimated lifetime risk of 1 in every two people $[1,2]$. The two most common types of skin cancer are basal cell carcinoma and squamous cell carcinoma, respectively, while malignant melanoma is less common, with an incidence of 1 in every $40[3,4]$. However, despite the lower prevalence, malignant melanoma remains the most common cause of skin-related cancer $[3,5]$. In the United States, it is estimated that skin cancer's average annual economic cost is $\$ 8.1$ billion, with a dramatic rise in the total cost compared with other cancers [6].

Research has shown that the average annual cost of skin cancer from 2002-2006 to 2007-2011 increased by $126.2 \%$, and the average annual cost of all other cancers increased by $25.1 \%$ [6]. Hence, the importance of interventions and strategies that aim to reduce the health and economic burden of skin cancer. One such strategy is improving patient health education that promotes sun-protective behaviors. Primary sun-protective behaviors involve the reduction of natural and artificial UV light exposure, the application of sunscreen with a good sun protection factor (SPF), wearing hats with adequate protection to the entire head, along with tightly woven clothing that covers the arms, torso, and legs [7]. At the same time, secondary sun-protective behaviors include the regular conduct of self-skin and total body skin examinations by physicians [4]. Reports suggest that avoidance of exposure to natural and artificial UV light could prevent more than 5 million cases of skin 
cancer yearly [8], and daily application of a sunscreen with SPF 15 or more could decrease the risk of squamous cell carcinoma by $40 \%$ and melanoma by $50 \%$ [9].

Researchers worldwide have continuously tried to address the problem behind the rising incidence of skin cancer, and many environmental and genetic causes have been discovered [10].

A study with nursing students revealed that only $8 \%$ of students performed the sun-protection recommendations, and this was the least correctly performed activity [11]. Accordingly, training the students in the medical-related fields, mainly those directed towards primary care, about the importance of sun-protective behaviors is crucial to decreasing skin cancer incidence. Primary care physicians possess more chances to conduct skin examinations and educate patients on sun-protective behaviors [12]; recent reports pointed out the importance of health education of medical students about the effect of sun exposure on human health [13-16].

The purpose of this study is to assess medical students' knowledge, attitude, and practice about skin cancer prevention and detection.

\section{Methodology}

This descriptive cross-sectional survey-based study was conducted in Jordanian medical schools between July and October 2021. The survey was conducted using a validated structured questionnaire developed by researchers with help from the literature review of similar published studies to cover critical areas. Moreover, the survey was validated by three experts from the departments of dermatology, general surgery, and public health at the same affiliated university, Yarmouk University, Faculty of Medicine. We have included the questionnaire in the revised manuscript.

The questionnaire consisted of 51 questions categorized to cover all survey targets. The first six questions were about the student's demographic data; the following 19 questions were meant to test the knowledge of the students about the risk factors of skin cancer in general, adding 26 questions about the impact of sun exposure on the skin and the behaviors of participants toward sun protection and early skin cancer signs. Participation in the study was voluntary, and consent was taken from each participant after explaining the purpose of the research. All medical students from all Jordanian medical schools who gave consent to participate in this study were included. The study was approved by the institutional board review at Yarmouk University, number $\mathrm{RD} / 119 / 12 / 1870$.

A structured online Google form was created to aid in data collection as a study tool. The online survey link was distributed through social media platforms, through universities' representatives, and universities' official emails. After that, data were collected and organized into an Excel document then imported to The Statistical Package for Social Sciences (SPSS) version 25, where coding and data analysis were performed. Descriptive statistical methods were used to evaluate the data using mean \pm SD for continuous variables and frequencies and percentages for categorical variables. Inferential statistics in the form of a Chi-Square test were done to evaluate the significance of the association between participants' gender and knowledge about skin cancer. $P$ values of less than 0.05 were considered to be statistically significant.

\section{Results}

A total of 1530 subjects were recruited for the study, representing around $10 \%$ of the entire student population at the time of the study. Females constituted $55.3 \%$ of the study participants (846), while 684 males were selected. The majority of the study population was found within the age group 20-23 (67.5\%). The study involved participants from the first year to the sixth year, with the fifth-year students representing the majority $(28.1 \%)$. Most of the students (44.4\%) scored very good degrees as their average academic rank, followed by excellent (32\%), good (22.5), and weak (1\%). Table 1.

Regarding their knowledge about skin cancer, most of the students have encountered a family history of skin cancer (97.9\%), and the majority of them considered themselves to possess proper knowledge $(81 \%)$. At the same time, the same percentage selected medical school as their source of information regarding skin cancer. About $46.9 \%$ of the participants correctly identified basal cell carcinoma as the most common type of skin cancer. The majority of them identified melanoma characteristics as a mole with an asymmetrical border $(63 \%)$, while more than half of the students selected it as changes in color (59.9\%). Table 2.

When testing the general knowledge about the risk factors of the disease, most of the participants (83.5\%) acknowledged going out during the hours of 10 am to $4 \mathrm{pm}$ without sun protection as a risk factor for the disease. More than half (58.7) considered the effect of smoking and alcohol in increasing the risk. Having fair skin was a risk in the opinion of $64 \%$, and exposure to ultraviolet radiation was identified by $95.2 \%$ of the participants as a risk. More than half $(59.5 \%, 57.8 \%$, and $57.4 \%)$ considered having lots of nevi, freckles, and moles in the body, tanning, and acquiring painful sunburn before 20 years old to be risk factors, respectively. Immunosuppressive agents were a risk in the responses of $71.2 \%$, while those not using sunscreens were correctly identified by $63 \%$. Other responses to general knowledge and risk factors are shown in Table 3.

Regarding the attitude toward the disease, most of the study subjects $(61.5 \%)$ claimed that they did not have any habit of doing a self-skin examination. Most of those who did not perform a self-skin examination (91\%) had never even thought of it, among the others who usually perform self-skin examinations. Most of them do the exam to look for new lesions (72\%), and early skin cancer detection (53.7\%). Half of the participants learned about skin self-examination from medical courses and lectures; others heard it from social media (28.9\%) and dermatologists (19.4\%). The rest of the attitude responses are shown in Table 4.

Only $20.3 \%$ stated that they always avoid the sun from 10 am to $4 \mathrm{pm}$, while only $9.4 \%$ and $19.1 \%$ wear hats or sunglasses when going out, respectively. Other responses to practice questions are demonstrated in Table 5. 
TABLE 1: Demographic and general information about study participants.

\begin{tabular}{|c|c|c|c|}
\hline & & $N$ & $N(\%)$ \\
\hline \multirow{4}{*}{ Age groups in years } & Less than 20 & 126 & 8.2 \\
\hline & $20-23$ & 1032 & 67.5 \\
\hline & $24-27$ & 368 & 24.1 \\
\hline & 28 or more & 4 & 0.3 \\
\hline \multirow{2}{*}{ Gender } & Female & 846 & 55.3 \\
\hline & Male & 684 & 44.7 \\
\hline \multirow{6}{*}{ Study year } & First-year & 82 & 5.4 \\
\hline & Second-year & 172 & 11.2 \\
\hline & Third-year & 174 & 11.4 \\
\hline & Fourth-year & 370 & 24.2 \\
\hline & Fifth-year & 430 & 28.1 \\
\hline & Sixth-year & 302 & 19.7 \\
\hline \multirow{4}{*}{ Average academic rank } & Weak & 16 & 1.0 \\
\hline & Good & 344 & 22.5 \\
\hline & Very good & 680 & 44.4 \\
\hline & Excellent & 490 & 32.0 \\
\hline \multirow{2}{*}{ Do you have a family history of skin cancer } & No & 1498 & 97.9 \\
\hline & Yes & 32 & 2.1 \\
\hline
\end{tabular}

No statistically significant association between study variables has been found.

\section{Discussion}

Skin cancer is among the most prevalent skin cancers worldwide and is a growing health concern in the Mediterranean region. Generally, cancers constitute the second most common cause of death, outnumbered only by cardiovascular diseases [17]. Since skin cancer can be prevented, given that many risk factors have been identified, the WHO has implemented strategies to control skin cancer by raising people's knowledge about skin cancer through health education [17], improving attitudes and performance. However, Romero-Collado A et al., who conducted their study among primary care nurses in Spain, found that only 11 out of 137 nursing students $(8.0 \%)$ performed sun protection recommendations. This was the least activity performed and reflects poor skills in health prevention according to skin cancer [11]. This highlights an additional point about the importance of health education about skin cancer: it is reasonable to work on improving primary and secondary prevention rather than the management of the disease, which, as an example, costs more than 400 million dollars every year in Australia [18].

The statistical analysis showed that the level of knowledge about skin cancer and its risk factors is generally reasonable. Nearly half of our participants correctly identified basal cell carcinoma as the most common type of skin cancer. A similar study among medical students showed a better percentage (67.8\%) [19]. Third of the participants correctly disagreed about the fact that tanning salons offer a safer alternative to tanning outdoor, although less than what is found by Ivanov (98.3\%), while only $20 \%$ agreed that having many moles increased the risk of having skin cancer, again the percentage is high compared to the American study $(71.9 \%)$ [19].
Sun exposure is a risk factor for skin cancer, especially in a region with rich sunlight like Jordan. The participants in the current study showed a considerable variability when asked about the risk factors that could lead to the occurrence of skin cancer, and most of them agreed that genetic factors play a role $(93.3 \%)$, a higher level than the study conducted in Italy (44.3\%). However, it is worth mentioning that it was done in secondary school rather than medical students, where proper knowledge about the disease might have already been conducted [20]. In addition, sun exposure during the day with high sunrays within protection was also a popular risk factor (83.5\%), slightly higher than a study done in Saudi Arabia where 77\% agreed [21].

More than half of the students stated that they did not have the habit of doing skin examinations, which is an unsatisfactory result given that the population under study was medical students. A similar issue was found among nurse practitioners, as only $22 \%$ feel confident in performing skin examinations on their patients, and $67 \%$ of them feel less confident in counseling their patients about it [10].

Regarding the practice of our study participants, it was average and unsatisfactory at some points. It is well known that ultraviolet radiation, particularly that of the wavelength $290-320 \mathrm{~nm}$, is a risk factor for skin cancer due to its DNAdamaging and immunosuppressive effects [22]. Although the association between UV light exposure and skin cancer was highly reported by our study participants (95.2\%), the results showed that only $20 \%$ of the students respected the time restrictions and avoided the sun during the day where maximum radiation levels are present.

Although $39.3 \%$ of them always use sunscreen, which is surprisingly lower compared to a similar study by MahmoodAbad, as $60 \%$ of the students under the study used sunscreen and lower than the $73 \%$ found in the Martin study and Suppa (78.7\%) [20,23]. Although a higher level of 
TABLE 2: General knowledge of participants about skin cancer mainly melanoma.

\begin{tabular}{|c|c|c|c|c|c|c|c|c|}
\hline & \multicolumn{6}{|c|}{ Gender } & \multirow{3}{*}{$p\left(X^{2}\right)$} \\
\hline & & \multicolumn{2}{|c|}{ Female } & \multicolumn{2}{|c|}{ Male } & \multicolumn{2}{|c|}{ Total } & \\
\hline & & $N$ & $\begin{array}{c}N \\
(\%)\end{array}$ & $N$ & $\begin{array}{c}N \\
(\%)\end{array}$ & $N$ & $\begin{array}{c}N \\
(\%)\end{array}$ & \\
\hline \multirow{2}{*}{ Do you have knowledge about skin cancer } & No & 138 & 16.3 & 152 & 22.2 & 290 & 19.0 & \multirow[t]{2}{*}{$0.003^{*}(8.6)$} \\
\hline & Yes & 708 & 83.7 & 532 & 77.8 & 1240 & 81.0 & \\
\hline \multirow{7}{*}{$\begin{array}{l}\text { What is your major source of information about skin } \\
\text { cancer }\end{array}$} & Books & 186 & 24.0 & 230 & 36.9 & 416 & 29.8 & \multirow[t]{7}{*}{$\begin{array}{c}<0.001^{*} \\
(38.9)\end{array}$} \\
\hline & Medical school & 626 & 80.9 & 506 & 81.1 & 1132 & 81.0 & \\
\hline & $\begin{array}{c}\text { Course outside medical } \\
\text { school }\end{array}$ & 36 & 4.7 & 36 & 5.8 & 72 & 5.2 & \\
\hline & Health professional & 120 & 15.5 & 108 & 17.3 & 228 & 16.3 & \\
\hline & Friend/relative & 31 & 4.0 & 33 & 5.3 & 64 & 4.6 & \\
\hline & Internet & 294 & 38.0 & 264 & 42.3 & 558 & 39.9 & \\
\hline & Media & 150 & 19.4 & 90 & 14.4 & 240 & 17.2 & \\
\hline \multirow{6}{*}{$\begin{array}{l}\text { According to your knowledge, what is the most common } \\
\text { form of skin cancer? }\end{array}$} & Angiosarcoma & 2 & 0.2 & 12 & 1.8 & 14 & 0.9 & \multirow{6}{*}{$\begin{array}{r}0.002^{*} \\
(18.9)\end{array}$} \\
\hline & Basal cell carcinoma & 408 & 48.2 & 310 & 45.3 & 718 & 46.9 & \\
\hline & Melanoma & 148 & 17.5 & 114 & 16.7 & 262 & 17.1 & \\
\hline & Squamous cell carcinoma & 158 & 18.7 & 160 & 23.4 & 318 & 20.8 & \\
\hline & T Cell lymphoma & 10 & 1.2 & 2 & 0.3 & 12 & 0.8 & \\
\hline & Don't know & 120 & 14.2 & 86 & 12.6 & 206 & 13.5 & \\
\hline \multirow{5}{*}{$\begin{array}{l}\text { How many moles (melanocytic nevi) does the average } \\
\text { person have? }\end{array}$} & 5 & 88 & 23.5 & 60 & 23.6 & 148 & 23.6 & \multirow[t]{5}{*}{$\begin{array}{r}0.003^{*} \\
(16.1)\end{array}$} \\
\hline & 10 & 88 & 23.5 & 90 & 35.4 & 178 & 28.3 & \\
\hline & 25 & 142 & 38.0 & 76 & 29.9 & 218 & 34.7 & \\
\hline & 50 & 50 & 13.4 & 20 & 7.9 & 70 & 11.1 & \\
\hline & 100 & 6 & 1.6 & 8 & 3.1 & 14 & 2.2 & \\
\hline \multirow{7}{*}{ What is the most common melanoma location? } & Head & 146 & 17.3 & 126 & 18.4 & 272 & 17.8 & \multirow[t]{7}{*}{$\begin{array}{l}0.025^{*} \\
(14.4)\end{array}$} \\
\hline & Palm and sole & 42 & 5.0 & 44 & 6.4 & 86 & 5.6 & \\
\hline & Trunk & 201 & 23.8 & 140 & 20.5 & 341 & 22.3 & \\
\hline & Legs & 60 & 7.1 & 34 & 5.0 & 94 & 6.1 & \\
\hline & Mucosa & 22 & 2.6 & 34 & 5.0 & 56 & 3.7 & \\
\hline & Arms & 84 & 9.9 & 84 & 12.3 & 168 & 11.0 & \\
\hline & Don't know & 290 & 34.3 & 222 & 32.5 & 512 & 33.5 & \\
\hline \multirow{5}{*}{ What are the melanoma characteristics } & $\begin{array}{c}\text { Change of color/several } \\
\text { colors }\end{array}$ & 554 & 65.5 & 362 & 52.9 & 916 & 59.9 & \multirow[t]{5}{*}{$\begin{array}{c}<0.001^{*} \\
(44.8)\end{array}$} \\
\hline & Wound that does not heal & 128 & 15.1 & 74 & 10.8 & 202 & 13.2 & \\
\hline & $\begin{array}{c}\text { Mole with asymmetric } \\
\text { borders }\end{array}$ & 562 & 66.4 & 402 & 58.8 & 964 & 63.0 & \\
\hline & Pigmented lesion & 552 & 65.2 & 420 & 61.4 & 972 & 63.5 & \\
\hline & Don't know & 154 & 18.2 & 144 & 21.1 & 298 & 19.5 & \\
\hline
\end{tabular}

practice was identified, there was still an area of ignorance toward sun exposure as a risk factor. In addition, the same percentage was found in a similar study among medical students in the USA [19].

As sun exposure is one of the risk factors of skin cancer, wearing long pants and long-sleeved clothes can be protective; this method of protection was utilized by $47.3 \%$ of the students, which is higher than the Italian study where only $7 \%$ of the participants used protective clothes [20].
In our study, the general knowledge and attitude toward skin cancer were generally good, given that the participants were medical students; their level of knowledge about the disease may already be good, and the sources of information were the most reliable ones. Conversely, the results of a similar study conducted among other students from different fields, including medical students, showed that the level of knowledge and attitude among the nonmedical students was lower than that of medical students [17]. 
TABLE 3: General knowledge about risk factors for skin cancer.

\begin{tabular}{|c|c|c|c|c|c|c|}
\hline & \multicolumn{4}{|c|}{$\begin{array}{l}\text { Don't } \\
\text { know/ } \\
\text { neutral }\end{array}$} & \multicolumn{2}{|c|}{ Agree } \\
\hline & $N$ & $\%$ & $N$ & $\%$ & $N$ & $\%$ \\
\hline Going out during the hours of 10.00 am to $4.00 \mathrm{pm}$ without sun protection & 98 & 6.4 & 154 & 10.1 & 1278 & 83.5 \\
\hline Smoking/alcohol use & 328 & 21.4 & 304 & 19.9 & 898 & 58.7 \\
\hline Having fair skin & 224 & 14.6 & 318 & 20.8 & 988 & 64.6 \\
\hline Exposure to ultraviolet radiation & 38 & 2.5 & 36 & 2.4 & 1456 & 95.2 \\
\hline Lots of nevus, freckles, and moles on the body & 294 & 19.2 & 326 & 21.3 & 910 & 59.5 \\
\hline Having never tanning skin type & 604 & 39.5 & 526 & 34.4 & 400 & 26.1 \\
\hline Solarium/tanning salons & 208 & 13.6 & 438 & 28.6 & 884 & 57.8 \\
\hline Having light-colored eyes & 626 & 40.9 & 424 & 27.7 & 480 & 31.4 \\
\hline Having red or blonde hair & 614 & 40.1 & 418 & 27.3 & 498 & 32.5 \\
\hline Having sun burns which are painful and bubbly before 20 years of age & 300 & 19.6 & 352 & 23.0 & 878 & 57.4 \\
\hline Exposure to petroleum, coal, or arsenic & 162 & 10.6 & 302 & 19.7 & 1066 & 69.7 \\
\hline Family history of skin cancer & 58 & 3.8 & 44 & 2.9 & 1428 & 93.3 \\
\hline Taking immunosuppressive treatment & 150 & 9.8 & 290 & 19.0 & 1090 & 71.2 \\
\hline Not using sunscreen & 174 & 11.4 & 392 & 25.6 & 964 & 63.0 \\
\hline You are adequately protected from UV rays with thin cloud cover & 588 & 38.4 & 362 & 23.7 & 580 & 37.9 \\
\hline Tanning salons offer a safe alternative to sun tanning outdoors & 598 & 39.1 & 598 & 39.1 & 334 & 21.8 \\
\hline People with many moles are at an increased risk of developing melanoma & 292 & 19.1 & 300 & 19.6 & 938 & 61.3 \\
\hline Wet clothing offers less protection against the sun than dry clothing & 452 & 29.5 & 746 & 48.8 & 332 & 21.7 \\
\hline $\begin{array}{l}\text { When you are swimming in a pool, the part underwater is protected from the sun since water reflects } \\
\text { most of the UV light }\end{array}$ & 426 & 27.8 & 492 & 32.2 & 612 & 40.0 \\
\hline Using self-tanning lotions or cream is an effective method for sun protection & 542 & 35.4 & 390 & 25.5 & 598 & 39.1 \\
\hline The ozone layer filters most of the ultraviolet type B but little of the A type & 144 & 9.4 & 734 & 48.0 & 652 & 42.6 \\
\hline A suntan offers adequate protection to prevent sunburn & 556 & 36.3 & 524 & 34.2 & 450 & 29.4 \\
\hline Chemical sunscreens give optimal protection as soon as they contact the skin & 534 & 34.9 & 396 & 25.9 & 600 & 39.2 \\
\hline Sunblock SPF mean (sun protective factor) & 82 & 5.4 & 430 & 28.1 & 1018 & 66.5 \\
\hline
\end{tabular}

TABLE 4: Attitudes toward skin self-examination.

\begin{tabular}{|c|c|c|c|}
\hline & & $N$ & $\%$ \\
\hline \multirow{2}{*}{$\begin{array}{l}\text { Your attitude toward skin protective behaviors and self-skin exam: do you have } \\
\text { the habit of doing the skin self-examination? }\end{array}$} & No & 942 & \\
\hline & Yes & 588 & \\
\hline \multirow{3}{*}{ If not, why? } & $\begin{array}{l}\text { I have learned about it but being scared of } \\
\text { finding something }\end{array}$ & 46 & \\
\hline & It is not necessary & 38 & \\
\hline & Never thought about it & 858 & \\
\hline \multirow{4}{*}{ What do you look for in the skin self-examination } & Changing mole & 406 & 69.0 \\
\hline & New mole & 350 & 59.5 \\
\hline & Nodule & 272 & 46.3 \\
\hline & New lesion & 426 & 72.4 \\
\hline \multirow{5}{*}{ Reasons for performing skin self-examination } & Early detection of skin cancer & 316 & 53.7 \\
\hline & Fear of skin cancer & 184 & 31.3 \\
\hline & Friend/relative had skin cancer & 68 & 11.6 \\
\hline & Peace of mind & 290 & 49.3 \\
\hline & Recommendation from doctor & 130 & 22.1 \\
\hline \multirow{6}{*}{ Where did you learn about skin self-examination } & Books & 88 & 15.0 \\
\hline & Dermatologist/health care professional & 114 & 19.4 \\
\hline & Friends/relatives & 42 & 7.1 \\
\hline & Medical courses and lectures & 294 & 50.0 \\
\hline & Internet & 210 & 35.7 \\
\hline & Social media & 170 & 28.9 \\
\hline
\end{tabular}




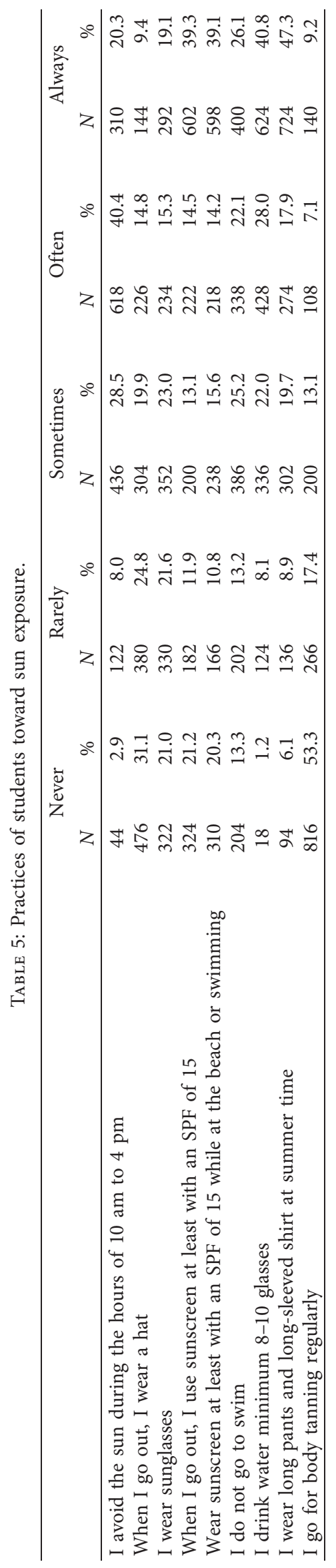




\section{Conclusion}

The general level of the medical students' knowledge of skin cancer and its risk factors appeared to be higher than what is found in other studies; it is reasonable as the study participants were medical students. However, the protective behavior from the sun was inadequate when compared to the level of knowledge reported. Additional education about the behavior toward sun exposure and protection against skin cancer may be needed to be implemented in their dermatology curriculum.

5.1. Limitations. The main limitation of this study is using an online questionnaire, which can lead to the possibility of self-reporting bias. However, we avoid this problem by using a large representative sample of medical students.

\section{Data Availability}

The data used to support the findings of this study are available from the corresponding author upon request.

\section{Ethical Approval}

The present study was designed in accordance with the ethical principles of the Declaration of Helsinki. The study protocol and design were approved by the institutional board review at Yarmouk University number (RD/119/12/ 1870).

\section{Consent}

All participants signed an informed consent form.

\section{Conflicts of Interest}

The authors report that they have no conflicts of interest with this study.

\section{Acknowledgments}

We would like to thank all dermatology residents for their support.

\section{References}

[1] Centers for Disease Control and Prevention, Melanoma of the Skin Statistics, CDC, Atlanta, GA, USA, 2021.

[2] J. K. Robinson, "Sun exposure, sun protection, and vitamin D," Journal of the American Medical Association. JAMA, vol. 294, pp. 1541-1543, 2005.

[3] American Academy of Dermatology, Types of Skin Cancer, American Academy of Dermatology, Rosemont, IL, USA, 2021.

[4] D. Y. Diao and T. K. Lee, "Sun-protective behaviors in populations at high risk for skin cancer," Psychology Research and Behavior Management, vol. 7, pp. 9-18, 2013.

[5] SEER Cancer Statistics Review, Previous Version-SEER Cancer Statistics Review 1975-2010, SEER Cancer Statistics Review, Bethesda, MD, USA, 2013.
[6] G. P. Guy, S. R. Machlin, D. U. Ekwueme, and K. R. Yabroff, "Prevalence and costs of skin cancer treatment in the U.S., 2002-2006 and 2007-2011," American Journal of Preventive Medicine, vol. 48, no. 2, pp. 183-187, 2015.

[7] Office of the Surgeon General, Surgeon General Call to Action to Prevent Skin Cancer, Office of the Surgeon General, Rockville, MD, USA, 2014.

[8] C. Facts, Cancer Statistics, World Health Organization, Geneva, Switzerland, 1979.

[9] A. Green, G. Williams, R. Neale et al., "Daily sunscreen application and betacarotene supplementation in prevention of basal-cell and squamous-cell carcinomas of the skin: a randomised controlled trial," Lancet, vol. 354, no. 9180, pp. 723-729, 1999.

[10] J. L. Blake and L. Malone, "Current behaviors, attitudes, and knowledge of nurse practitioners in primary care toward skin cancer screening/prevention," Journal of the Dermatology Nurses' Association, vol. 6, no. 2, pp. 65-69, 2014.

[11] A. Romero-Collado, A. Baltasar-Bagué, N. Puigvert-Viu, C. Rascón-Hernán, and E. Homs-Romero, "Using simulation and electronic health records to train nursing students in prevention and health promotion interventions," Nurse Education Today, vol. 89, Article ID 104384, 2020.

[12] J. M. Goulart, E. A. Quigley, S. Dusza et al., "and INFORMED (INternet curriculum FOR Melanoma Early Detection) Group Skin cancer education for primary care physicians: a systematic review of published evaluated interventions," Journal of General Internal Medicine, vol. 26, pp. 1027-1035, 2011.

[13] A. Isvy, A. Beauchet, P. Saiag, and E. Mahé, "Medical students and sun prevention: knowledge and behaviours in France," Journal of the European Academy of Dermatology and Venereology, vol. 27, no. 2, 2013.

[14] A. Garg, J. Wang, S. B. Reddy et al., "and Integrated Skin Exam Consortium Curricular factors associated with medical students' practice of the skin cancer examination: an educational enhancement initiative by the integrated skin exam consortium," JAMA Dermatology, vol. 150, no. 8, pp. 850-855, 2014.

[15] M. J. Gooderham and L. Guenther, "Impact of a sun awareness curriculum on medical students' knowledge, attitudes, and behaviour," Journal of Cutaneous Medicine and Surgery, vol. 3, no. 4, pp. 182-187, 1999.

[16] L. Kirk and S. Greenfield, "Knowledge and attitudes of UK university students in relation to ultraviolet radiation (UVR) exposure and their sun-related behaviours: a qualitative study," BMJ Open, vol. 7, no. 3, 2017.

[17] S. S. M. MahmoodAbad, M. T. Noorbala, M. Mohammadi, Z. Rahaei, and M. H. Ehrampush, "Knowledge, attitude, and performance of students toward skin cancer in Yazd, 2009," International Journal of Dermatology, vol. 50, no. 10, pp. 1262-1265, 2011.

[18] W. H. McCarthy and H. M. Shaw, "Skin cancer in Australia," Medical Journal of Australia, vol. 150, no. 9, pp. 469-470, 1989.

[19] N. N. Ivanov, A. Swan, E. H. Guseman, J. Whipps, L. L. Jensen, and E. A. Beverly, "Medical students' knowledge, attitudes, and behaviors with regard to skin cancer and sun-protective behaviors," Journal of Osteopathic Medicine, vol. 118, no. 7, pp. 444-454, 2018.

[20] M. Suppa, S. Cazzaniga, M. C. Fargnoli, L. Naldi, and K. Peris, "Knowledge, perceptions and behaviours about skin cancer and sun protection among secondary school students from Central Italy," Journal of the European Academy of Dermatology and Venereology, vol. 27, no. 5, pp. 571-579, 2013. 
[21] H. M. Al-Atif, "A cross-sectional survey of knowledge of skin cancer in Saudi Arabia," Dermatology Practical and Conceptual, vol. 11, no. 3, pp. 1-6, 2021.

[22] I. G. Castilho, M. A. A. Sousa, and R. M. S. Leite, "Photoexposure and risk factors for skin cancer: an evaluation of behaviors and knowledge among university students," Anais Brasileiros de Dermatologia, vol. 85, no. 2, pp. 173-178, 2010.

[23] R. H. Martin, "Relationship between risk factors, knowledge and preventive behaviour relevant to skin cancer in general practice patients in South Australia," British Journal of General Practice: The Journal of the Royal College of General Practitioners, vol. 45, no. 396, pp. 365-367, 1995. 